Gut, 1987, 28, 929-934

\title{
Gastro-oesophageal reflux and the migrating motor complex
}

\author{
R C GILl, J E KELLOW, AND DAVID L WINGATE \\ From the Gastrointestinal Science Research Unit, London Hospital Medical College, London
}

SUMmARY Distal oesophageal $\mathrm{pH}$ and gastroduodenal motor activity were recorded simultaneously throughout nocturnal $(2330-0830 \mathrm{~h})$ and diurnal $(0830-1730 \mathrm{~h})$ periods of fasting in seven healthy subjects. At night, episodes of gastro-oesophageal reflux (GOR) accounted for $1 \cdot 2 \pm 0.7 \%$ of recording time. Periods of gastric motor activity, representing the gastric component of the migrating motor complex (MMC), recurred every $78 \pm 31 \mathrm{~min}$ during the night and were interspersed with periods of gastric motor quiescence. Nocturnal episodes of GOR during periods of gastric motor activity were of longer duration $(p<0.001)$ and more frequent $(p<0.005)$ than during periods of gastric motor quiescence. At night, periodic gastric motor activity was thus correlated $(\mathrm{p}<0 \cdot 001)$ with an increase in the duration and number of GOR episodes and associated with a 100 -fold increase in oesophageal acid exposure. During the day, the gastric component of the MMC, recurring every $131 \pm 64 \mathrm{~min}$, was correlated $(\mathrm{p}<0.02)$ with an increase in the duration and number of GOR episodes, and a three fold increase in oesophageal acid exposure. Further, $89 \%$ of nocturnal, and $83 \%$ of diurnal gastric MMCs were temporally associated with episodes of GOR. We conclude that fasting episodes of GOR occur coincidentally with the gastric component of the MMC.

In health and disease most gastro-oesophageal reflux (GOR) occurs postprandially. ${ }^{1-4}$ Recent studies suggest, however, that nocturnal episodes of GOR, which also occur in healthy subjects, ${ }^{256}$ are an important factor in the pathogenesis of gastrooesophageal reflux disease. ${ }^{17 x}$ Such nocturnal episodes of GOR are associated with a temporary decrease in the depth of sleep ${ }^{256}$ and a transient inappropriate relaxation of the lower oesophageal sphincter (LOS). ${ }^{2}$ Such periods of arousal from deep sleep recur cyclically and are marked by a characteristic EEG pattern. ${ }^{411}$ As with distal oesophageal acidification, ${ }^{12}$ it is likely that nocturnal episodes of GOR result in arousal from sleep.

Several other nocturnal periodic phenomena, such as body movement, ${ }^{41113}$ swallowing ${ }^{5}$ and gastric motor activity, ${ }^{11} 13-15$ are also associated with arousal from sleep. The cyclic recurrence of gastric motor activity is of particular interest in view of the

Address for correspondence: Dr Richard C Gill, Gastrointestinal Science Research Unit, 26 Ashfield Street, London E1 2AJ.

Received for publication 26 January 1987 possibility that forceful gastric contractions might give rise to GOR. ${ }^{*}$ These periods of gastric motor activity represent the gastric component of the migrating motor complex (MMC). The MMC is a characteristic feature of fasting gastrointestinal motor activity which occurs most frequently at night. ${ }^{16}$ On this evidence, it might be anticipated that nocturnal episodes of GOR will occur in temporal association with the gastric component of the MMC; this does not appear to have been investigated.

In the present study, 24-hour monitoring of distal oesophageal $\mathrm{pH}$ and gastroduodenal motor activity was undertaken in healthy subjects to ascertain whether episodes of GOR occur in association with the gastric component of the MMC. The gastric component of the MMC was recognised as that period of fasting during which large amplitude gastric contractions were present, including both phase 2 and phase 3 activity, and which preceded the duodenal activity front. During the nocturnal recording period we made no EEG assessment of the stage of sleep. 


\section{Methods}

SUBJECTS

Seven healthy volunteers (five men, two women) with a mean age of $24 \pm 5$ years participated in this study after informed consent was obtained. None had symptoms or a history of gastrointestinal disease, nor was any participant taking medication. Subjects refrained from smoking or alcohol ingestion for 24 hours before the study. The experimental protocol for this study was approved by the Ethics Committee of the Tower Hamlets Area Health Authority.

OESOPHAGEAL $\mathrm{pH}$

A glass $\mathrm{pH}$ microelectrode (Russel $\mathrm{pH}$, Auchtermuchty, Scotland) was passed transnasally into the distal oesophagus and positioned $5 \mathrm{~cm}$ above the proximal margin of the manometrically defined LOS. A silver-silver chloride reference electrode (Medicotest, Olstykke, Denmark) was attached suprasternally. A microprocessor controlled data logger $(\mathrm{pH}$ 100, Gaeltec Research, Dingwall, Scotland) was used to sample oesophageal $\mathrm{pH}$ at $10 \mathrm{sec}$ intervals throughout the 24-hours period, data being stored in a 32K random access memory. ${ }^{17}$ Oesophageal $\mathrm{pH}$ was also recorded directly by a $\mathrm{pH}$ meter (Type $\mathrm{PH} 25$, Radiometer, Copenhagen, Denmark), the output of which was recorded on a polygraph (Graphtec Linearcorder WR 3101, Graphtec Corp, Japan).

\section{MANOMETRY}

A catheter assembly consisting of four fused polyethylene tubes (ID $0.6 \mathrm{~mm}$, OD $1.1 \mathrm{~mm}$ ) was used to record intraluminal pressures from the lower oesophageal sphincter, gastric antrum and two sites in the duodenum. Each catheter had a lateral opening equal to the internal diameter of the tube and was closed distal to this opening with a metal marker which enabled fluoroscopic localisation of the recording orifices, positioned $1,11,26$, and $41 \mathrm{~cm}$ from the distal end. The catheter was introduced transnasally and positioned so that the most orad recording orifice lay within the lower oesophageal sphincter. Each recording orifice was constantly perfused with water at a rate of $0.1 \mathrm{ml} / \mathrm{min}$ using a pneumohydraulic pump (Arndorfer Medical Specialties, Greendale, W1, USA). Pressures were transmitted to external pressure transducers (Gaeltec S8b, Gaeltec Ltd, Skye, Scotland), the output of which was recorded on the polygraph.

EXPERIMENTAL PROTOCOL

Subjects were intubated 12 hours before the study period. After an overnight fast, simultaneous manometric and $\mathrm{pH}$ recordings were made for the subsequent 24 hour period starting at $0830 \mathrm{~h}$. Subjects were seated and awake during the day, remaining fasted until a $540 \mathrm{kcal}$ meal (consisting of $125 \mathrm{~g}$ roast chicken, $14 \mathrm{~g}$ mashed potato, $85 \mathrm{~g}$ peas, $28 \mathrm{~g}$ cheddar cheese and a dessert of $30 \mathrm{~g}$ ice cream) was eaten at $1730 \mathrm{~h}$. Recordings continued throughout the night in the presence of an observer who reported that all subjects were supine and asleep by $2330 \mathrm{~h}$. Studies were concluded at $0830 \mathrm{~h}$ when the subjects were awoken.

DATA ANALYSIS

The study was considered as comprising a nine hours diurnal fasting period $(0830-1730 \mathrm{~h})$, a nine hours nocturnal fasting period $(2330-0830 \mathrm{~h})$ and a three hour postprandial period (1730-2030 h). Data from each of these periods were analysed separately.

\section{OESOPHAGEAL $\mathrm{pH}$}

Recordings obtained during the 24-hours study were transferred from the logger to a computer (Apricot PC, ACT Computers Ltd, Halesowen, England), stored on magnetic disk and plotted using a dot matrix printer (Mannesman Tally, Japan). These, together with the direct recordings of distal oesophageal $\mathrm{pH}$, were analysed visually by two observers. An episode of GOR was defined as a decrease in $\mathrm{pH}$ to $<4$ for at least 10 seconds. ${ }^{18}$ The number, duration and frequency of GOR episodes, and the percentage of recording time for which they accounted, were determined for each study period.

\section{MANOMETRY}

Recordings were analysed visually by two observers. During fasting, the gastric component of the MMC was recognised as a period of at least five minutes duration during which large amplitude $(>20 \mathrm{~mm} \mathrm{Hg})$ contractions occurred at a frequency of $1-3 / \mathrm{min}$. This preceded the duodenal activity front, recognised as being of at least three minutes duration during which contractions occurred at a frequency of $11-13 / \mathrm{min} .^{19}$ The MMC cycle length in both the stomach and in the duodenum was determined. The duration of the gastric component of the MMC, and the amplitude of gastric contractions, was measured.

RELATIONSHIP BETWEEN FASTING OESOPHAGEAL PH AND MANOMETRY

The percentage of nocturnal and diurnal recording time occupied by gastric motor activity associated with the MMC was determined. Nocturnal and diurnal episodes of GOR concomitant with either gastric motor activity or gastric motor quiescence were analysed separately. The number and duration of these GOR episodes and the percentage of recording time for which they accounted were determined. The incidence of GOR episodes was then 
correlated with the occurrence of gastric motor activity. Finally, the periods of gastric motor activity both with and without concomitant episodes of GOR were noted.

STATISTICAL ANALYSIS

Data presented throughout this study have been expressed as mean $\pm \mathrm{SD}$; statistical significance was assessed using Student's $t$ test for paired data. Correlation was assessed by computing a contingency coefficient $(\mathrm{C})$ and determining its significance using the $\chi^{2}$ test. ${ }^{20}$

\section{Results}

OESOPHAGEAL $\mathrm{pH}$

During both nocturnal and diurnal periods of fasting, episodes of GOR were observed in each subject (Fig. 1). A total of 185 reflux events were noted during fasting. These were of longer duration at night than during the day $(46 \pm 30 v 25 \pm 13 \mathrm{sec} ; \mathrm{p}<0.005)$, but occurred less frequently $\left(0.9 \pm 0.4 \vee 1.6 \pm 0.4 \mathrm{~h}^{-1}\right.$; $p<0.01)$. Thus, the percentage of time accounted for by GOR episodes did not vary between nocturnal and diurnal fasting periods $(1.2 \pm 0.7 v 1.1 \pm 0.5 \%$; $p>0 \cdot 4)$. A total of 66 reflux episodes were noted during the postprandial period (representing $40 \%$ of the number of GOR episodes). Postprandial episodes of GOR had a duration of $43 \pm 25 \mathrm{sec}$ and occurred with a frequency of $3 \cdot 2 \pm 0 \cdot 8 \mathrm{~h}^{-1}$. These GOR episodes accounted for $3 \cdot 7 \pm 1.6 \%$ of recording time, a greater percentage $(\mathrm{p}<0.001)$ than during fasting.
MANOMETRY

During fasting, each subject exhibited cyclic gastroduodenal motor activity. A total of 88 MMCs were observed in the duodenum, a gastric component being present in $92 \%$ of diurnal, and $85 \%$ of nocturnal, MMCs. Migrating motor complex cycle length was shorter at night than during the day, both in the stomach $(78 \pm 31 v 131 \pm 64 \mathrm{~min} ; \mathrm{p}<0.001)$ and duodenum (66 $\pm 27 v 122 \pm 58 \mathrm{~min} ; \mathrm{p}<0 \cdot 001)$. The duration of the gastric component of the MMC was also shorter at night, however, than during the day $(33 \pm 18 \vee 43 \pm 27 \mathrm{~min} ; \mathrm{p}<0 \cdot 01)$. Thus the gastric component of the MMC occupied $43 \pm 12 \%$ of nocturnal, and $38 \pm 13 \%$ of diurnal, recording time; these values were not different $(p>0 \cdot 4)$. The amplitude of gastric contractions associated with the MMC did not vary between nocturnal and diurnal periods $(27 \pm 9 v 31 \pm 8 \mathrm{~mm} \mathrm{Hg} ; \mathrm{p}>0 \cdot 4)$.

RELATIONSHIP BETWEEN FASTING OESOPHAGEAL PH AND MANOMETRY

During periods of gastric motor activity, episodes of nocturnal (Fig. 2) and diurnal (Fig. 3) GOR were of longer duration $(\mathrm{p}<0.001)$, and were more frequent $(p<0.005)$, than during the intervening periods of gastric motor quiescence. Thus, GOR episodes accounted for a greater proportion $(p<0.005)$ of nocturnal and diurnal recording time during periods of gastric motor activity than during gastric motor quiescence (Table). Episodes of GOR during nocturnal gastric motor activity were longer $(p<0.005)$, but no more frequent $(p>0.25)$, than those observed during diurnal gastric motor activity.

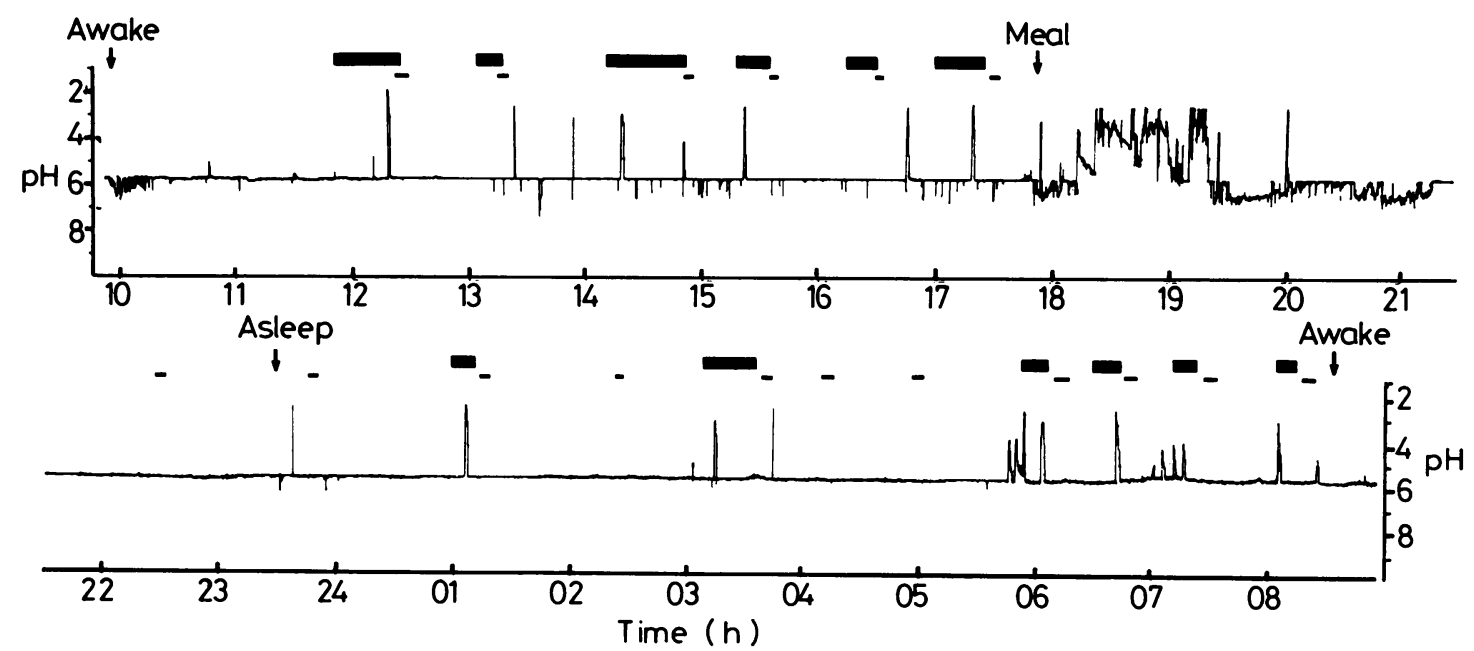

Fig. 1 24-h record of distal oesophageal pH starting at 1000 am in a fasting healthy subject. Periods of gastric (upper) and duodenal (lower) motor activity associated with the migrating motor complex (MMC) are indicated above the pH trace. Note coincidence of gastro-oesophageal reflux episodes and gastric components of the MMC throughout both diurnal and nocturnal fasts. 

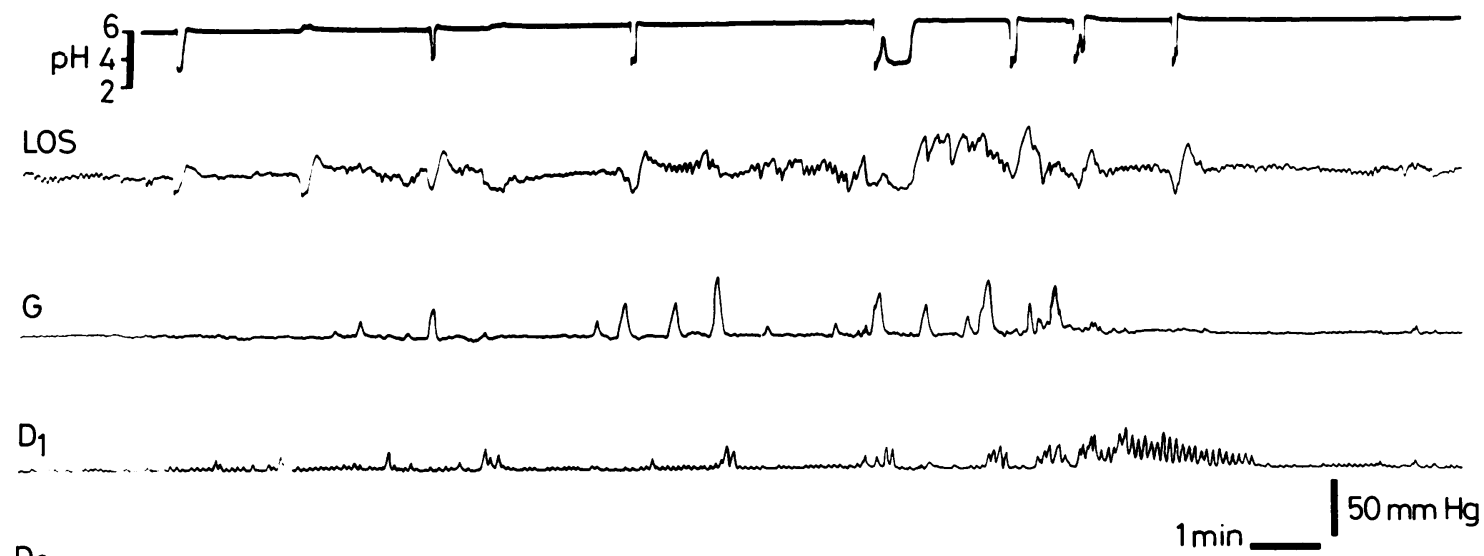

$\mathrm{D}_{2}$

Fig. 2 Nocturnal recording of distal oesophageal pH in a healthy subject during a migrating motor complex (MMC). Manometric recordings were obtained from the lower oesophageal sphincter (LOS), gastric antrum (G) and two sites in the duodenum (D). Two episodes of gastro-oesophageal reflux $(\mathrm{pH}<4$ for $>10 \mathrm{sec})$ were observed during the gastric component of the MMC. Relaxation of the LOS occurred concurrent with the first of these episodes.

Thus, GOR episodes accounted for a greater proportion $(p<0.05)$ of nocturnal than of diurnal periods of gastric motor activity (Table). During gastric motor quiescence, the duration of GOR episodes did not differ $(p>0 \cdot 25)$ between nocturnal and diurnal periods, although they occurred less frequently $(p<0 \cdot 001)$ at night. Thus, during periods of gastric motor quiescence, GOR episodes accounted for a lesser proportion $(p<0.001)$ of nocturnal than of diurnal recording time (Table).

Nocturnally, periodic gastric motor activity was correlated with an increase in the duration $(\mathrm{C}=0.52$; $\mathrm{p}<0.001)$, and number $(\mathrm{C}=0.46 ; \mathrm{p}<0.001)$, of GOR episodes. Further, diurnal periodic gastric motor activity was also correlated with an increase in the duration $(\mathrm{C}=0 \cdot 31 ; \mathrm{p}<0 \cdot(001)$, and number $(\mathrm{C}=0 \cdot 21$; $\mathrm{p}<0.02)$, of GOR episodes. Episodes of GOR were not correlated with MMCs which lacked a gastric component (Fig. 4). Indeed, 57\% (57/100) of diurnal fasting, and $95 \%(81 / 85)$ of nocturnal, GOR episodes were associated with periods of gastric motor activity. Finally, $83 \%(24 / 29)$ of diurnal, and $89 \%$ (43/48) of nocturnal, periods of gastric motor activity were temporally associated with episodes of GOR.

\section{Discussion}

The major finding of the present study was the coincidence of fasting episodes of GOR and the gastric component of the MMC. This relationship

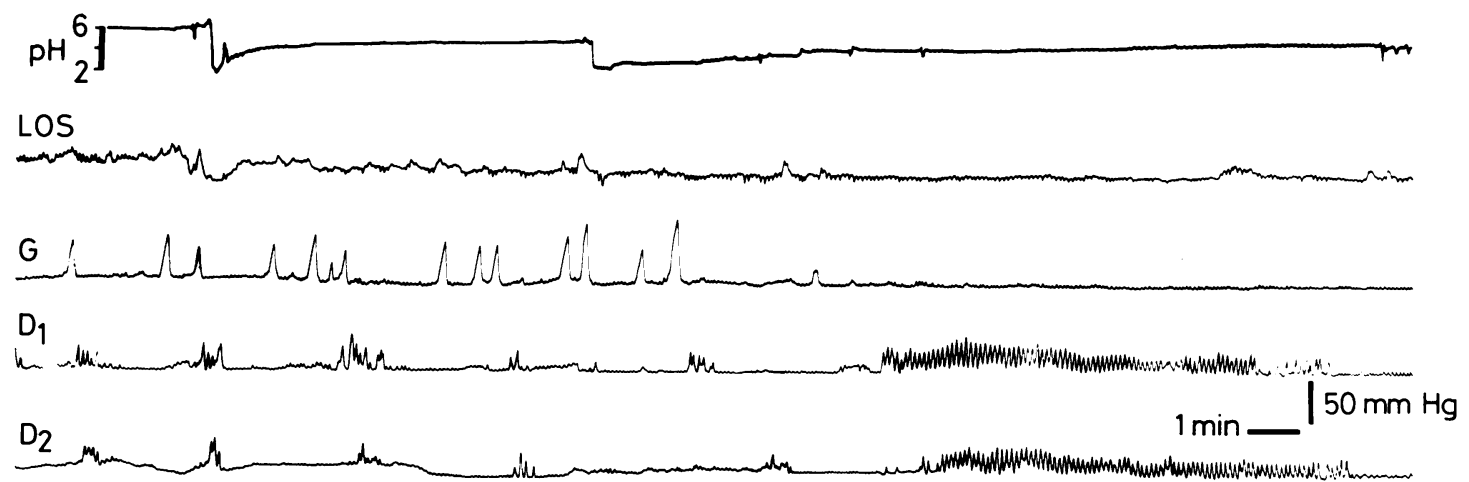

Fig. 3 Diurnal recording of distal oesophageal pH in a healthy fasting subject during a migrating motor complex (MMC). Manometric recording sites were designated as in Figure 2. One episode of gastro-oesophageal reflux $(\mathrm{pH}<4$ for $>10$ sec $)$ occurred during the gastric component of the $M M C$. 
Table Characteristics of nocturnal and diurnal gastrooesophageal reflux episodes during fasting periods of gastric motor activity and motor quiescence

\begin{tabular}{lccccc}
\hline & \multicolumn{2}{c}{ Gastric motor activity } & & \multicolumn{2}{c}{ Gastric motor quiescence } \\
\cline { 2 - 3 } \cline { 5 - 6 } \cline { 5 - 6 } & Nocturnal & Diurnal & & Nocturnal & Diurnal \\
\hline Duration (sec) & $50 \pm 29$ & $30 \pm 14$ & & $10 \pm 5$ & $18 \pm 9$ \\
Frequency/hour & $3 \cdot 0 \pm 1 \cdot 8$ & $2 \cdot 4 \pm 0 \cdot 7$ & & $0 \cdot 12 \pm 0 \cdot 11$ & $1 \cdot 1 \pm 0 \cdot 6$ \\
Time pH $<4(\%)$ & $3 \cdot 9 \pm 1 \cdot 7$ & $2 \cdot 0 \pm 0 \cdot 8$ & & $0 \cdot 03 \pm 0 \cdot 03$ & $0 \cdot 6 \pm 0 \cdot 4$ \\
\hline
\end{tabular}

was most marked nocturnally, when MMC related episodes of GOR were of longest duration, and GOR during gastric motor quiescence was least frequent. Our findings in respect to the incidence and duration of GOR episodes, and the percentage of time for which they accounted, are consistent with previous reports of GOR in healthy subjects, both during nocturnal ${ }^{1256}$ and diurnal ${ }^{421}$ fasting, and also postprandially. $1+1 \times 22$

We defined the gastric component of the MMC as a period of large amplitude gastric contractions preceding the duodenal activity front. ${ }^{19}$ This was considered appropriate as contractions during the gastric activity front are sporadic, ${ }^{23}$ preventing precise identification of phase 2 and phase 3 components. In confirmation of previous reports, ${ }^{1519}$ we observed that a gastric component preceded $87 \%$ of duodenal MMCs. Episodes of GOR were unlikely to be the consequence of a manometric assembly being positioned across the LOS, as this has been shown to have no effect on the frequency or duration of reflux episodes. $^{321}$

There would appear to be two mechanisms by which episodic GOR might be related to fasting

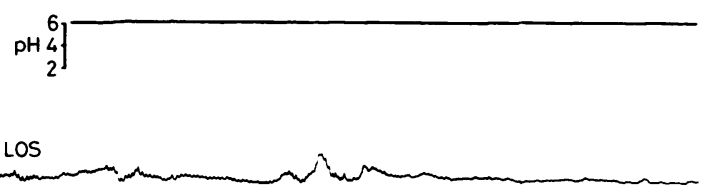

G

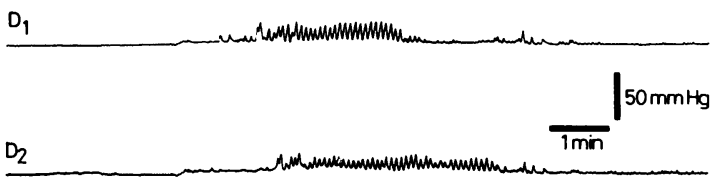

Fig. 4 Nocturnal recording of distal oesophageal $p H$ in a healthy subject during a migrating motor complex (MMC) lacking a gastric component. Manometric recording sites were designated as in Figure 2. Note the absence of gastrooesophageal reflux. periodic gastric motor activity. First, it is possible that forceful gastric contraction might increase intragastric pressure and result in retropulsion of gastric content through the LOS, as has been observed in dogs. ${ }^{24}$ Operation of this mechanism during the gastric component of the MMC would appear to be at variance with the concept that phasic contractions of the LOS occur concurrently with those of the proximal stomach during fasting..$^{2.28}$ Recent evidence suggests, however, that marked increases in intragastric pressure may result in reflux irrespective of LOS relaxation. ${ }^{4}$

It is perhaps more likely that fasting gastric contractions provoke transient inappropriate relaxations of the LOS and hence increase the likelihood of GOR. This would account for the significant proportion of those LOS relaxations which occur independently of coexistent motor activity in the body of the oesophagus. ${ }^{2+}$ In this context, it has been shown that the afferent discharge of gastric mechanoreceptors may be modulated by contraction of either the proximal or distal stomach. ${ }^{24}{ }^{310}$ Stimulation of these receptors by forceful gastric contraction associated with the MMC might, by activation of vagovagal reflexes, modify efferent vagal activity ${ }^{3132}$ and thus lead to inappropriate relaxation of the LOS.$^{33} \mathrm{In}$ this regard, gastric distension has recently been reported to increase the incidence of such transient inappropriate relaxations of the LOS, a finding attributed to activation of vago-vagal reflex pathways..$^{3+35}$

The occurrence of forceful gastric contractions, "13-15 transient inappropriate relaxations of the LOS, ${ }^{2}$ and swallowing activity ${ }^{5}$ have all been associated with interruption of deep sleep. These associations would be expected if fasting gastric contractions, either with or without concurrent relaxation of the LOS, were to result in GOR, consequent arousal from sleep, and subsequent initiation of swallowing activity. Indeed, distal oesophageal acidification results in arousal from sleep ${ }^{5612}$ and initiation of swallowing activity. ${ }^{512}$ In pathological GOR, it has been suggested that failure of this acid arousal mechanism results in prolonged exposure of the oesophageal mucosa to refluxate. ${ }^{12}$ Gastro-oesophageal reflux occurring during the gastric MMC would be most likely to result in mucosal damage as acid $^{3637}$ and pepsin ${ }^{36}$ secretion is increased at this time.

\section{References}

1 Demeester TR, Johnson LF, Joseph GJ, Toscano MS, Hall AW, Skinner DB. Patterns of gastroesophageal reflux in health and disease. Ann Surg 1976; 184: 459-70. 
2 Dent J, Dodds WJ, Friedman RH, et al. Mechanism of gastroesophageal reflux in recumbent asymptomatic human subjects. J Clin Invest 1980; 65: 256-67.

3 Dodds WJ, Dent J, Hogan WJ, et al. Mechanisms of gastroesophageal reflux in patients with reflux esophagitis. N Engl J Med 1982; 307: 1547-52.

4 Baldi F, Ferrarini F, Balestra R, et al. Oesophageal motor events at the occurrence of acid reflux and during endogenous acid exposure in healthy subjects and in patients with oesophagitis. Gut 1985; 26: 336-41.

5 Wallin L, Madsen T. 12-hour simultaneous registration of acid reflux and peristaltic activity in the oesophagus. Scand J Gastroenterol 1979; 14: 561-6.

6 Hughes DM, Spier S, Rivlin J, Levison H. Gastroesophageal reflux during sleep in asthmatic patients. J Pediatr 1983; 102: 666-72.

7 Dodds WJ, Hogan WJ, Miller WN. Reflux esophagitis. Am J Dig Dis 1976; 21: 49-67.

8 Dodds WJ, Hogan WJ, Helm JF, Dent J. Pathogenesis of reflux esophagitis. Gastroenterology 1981; 81: 376-94.

9 Dement W, Kleitman N. Cyclic variations in EEG during sleep and their relation to eye movement, body motility, and dreaming. Electroencephalogr Clin Neurophysiol 1957; 9: 673-99.

10 Sassin JF, Johnson LC. Body motility during sleep and its relation to the K-complex. Exp Neurol 1968; 22: 133-44.

11 Finch PM, Ingram DM, Henstridge JD, Catchpole BN. Relationship of fasting gastroduodenal motility to the sleep cycle. Gastroenterology 1982; 83: 605-12.

12 Orr WC, Johnson LF, Robinson MG. Effect of sleep on swallowing, esophageal peristalsis, and acid clearance. Gastroenterology 1984; 86: 814-9.

13 Wada T. An experimental study of hunger in its relation to activity. Arch Psychol 1922; 8: 1-65.

14 Baust W, Rohrwasser W. Das Verhalten von $\mathrm{pH}$ und Motilitat des Magens im naturlichen Schlaf des Menschen. Pflugers Arch 1969; 305: 229-40.

15 Evans DF, Foster GE, Hardcastle JD. The motility of the human antrum and jejunum during the day and during sleep: an investigation using a radiotelemetry system. In: Wienbeck M, ed. Motility of the digestive tract. New York: Raven Press, 1982: 185-92.

16 Thompson DG, Archer L, Green WJ, Wingate DL. Fasting motor activity occurs during a day of normal meals in healthy subjects. Gut 1981; 22: 489-92.

17 Vitale GC, Cheadle WG, Sadek S, Michel ME, Cuschieri A. Computerized 24-hour ambulatory esophageal pH-monitoring and esophagogastroduodenoscopy in the reflux patient. Ann Surg 1984; 200: 724-8.

18 Fink SM, McCallum RW. The role of prolonged esophageal $\mathrm{pH}$ monitoring in the diagnosis of gastroesophageal reflux. JAMA 1984; 252: 1160-4.

19 Kellow JE, Borody TJ, Phillips SF, Tucker RL, Haddad AC. Human interdigestive motility: variations in patterns from esophagus to colon. Gastroenterology 1986; 91 : 386-95.
20) Siegel S. Non-parametric statistics. New York: McGraw Hill, 1956.

21 Corazziari E, Bontempo I, Anzini F, Torsoli A. Motor activity of the distal oesophagus and gastro-oesophageal reflux. Gut 1984; 25: 7-13.

22 Kaye MD. Postprandial gastro-oesophageal reflux in healthy people. Gut 1977; 18: 709-12.

23 Gill RC, Pilot M-A, Thomas PA, Wingate DL. Organization of fasting and postprandial myoclectric activity in stomach and duodenum of conscious dogs. Am J Physiol 1985; 249: G655-61.

24 Sarna SK, Gleysteen JJ, Ryan RP. Fundic motor activity and its role in gastroesophageal reflux. [Abstract]. Gastroenterology 1986; 90: 1615.

25 Diamant NE, Akin AN. Effect of gastric contractions on the lower esophageal sphincter. Gastroenterology 1972; 63: $38-44$.

26 Itoh Z, Honda R, Aizawa I, Takeuchi S, Hiwatashi K, Couch EF. Interdigestive motor activity of the lower esophageal sphincter in the conscious dog. Am J Dig Dis 1978; 23: 239-47.

27 Lux G, Lederer P, Femppel J, Rosche W, Domschke W. Spontaneous and 13-NLE-motilin-induced interdigestive motor activity of esophagus, stomach and small intestine in man. In: J Christensen, ed. Gastrointestinal motility. New York: Raven Press, 1980: 269-77.

28 Dent J, Dodds WJ, Sekiguchi T, Hogan WJ, Arndorfer RC. Interdigestive phasic contractions of the human lower esophageal sphincter. Gastroenterology 1983; 84: 453-60.

29 Andrews PLR, Grundy D, Scratcherd T. Vagal afferent discharge from mechanoreceptors in different regions of the ferret stomach. J Physiol 1980; 298: 513-24.

30 Mei N. Sensory structures in the viscera. In: Ottoson DF, ed. Progress in sensory physiology. Berlin: Springer-Verlag, 1983: 1-42.

31 Davison JS, Grundy D. Modulation of single vagal efferent fibre discharge by gastrointestinal afferents in the rat. J Physiol 1978; 284: 69-82.

32 Roman C, Gonella J. Extrinsic control of digestive tract motility. In: Johnson LR, ed. Physiology of the gastrointestinal tract. New York: Raven Press, 1981: 289-333.

33 Paterson WG, Rattan S, Goyal RK. Experimental induction of isolated lower esophageal sphincter relaxation in anesthetized opossums. J Clin Invest 1986; 77: 1187-93.

34 Holloway RH, Hongo M, Berger K, McCallum RW. Gastric distension: a mechanism for postprandial gastroesophageal reflux. Gastroenterology 1985; 89: 779-84.

35 Kahrilas PJ, Dodds WJ, Dent J, Wyman JB, Hogan WJ, Arndorfer RC. Upper esophageal sphincter function during belching. Gastroenterology 1986; 91: 133-40.

36 Vantrappen GR, Peeters TL, Janssens J. The secretory component of the interdigestive migrating motor complex in man. Scand J Gastroenterol 1979; 14: 663-7.

37 Nakaya M, Suzuki T, Arai $H$, Itoh Z. Interdigestive cyclic gastric acid secretion controlled by gastrin and motilin. [Abstract]. Dig Dis Sci 1984; 29: 57S 